\title{
Agile Change to Digital Teaching during and after Corona Pandemic for Flipped Classroom Courses: An Overview of Tasks and Responsibilities
}

\author{
Christin Voigt ${ }^{(\varpi)}$, Linda Blömer, Jonas Kötter and Uwe Hoppe \\ University of Osnabrueck, Germany \\ christin.voigteuni-osnabrueck.de
}

\section{ABSTRACT}

The Corona Pandemic has a major impact on teaching at universities. Various stakeholders have to face new challenges when face-to-face courses are no longer feasible. The management of higher education institutions, teachers and their teams as well as the IT and didactics support are called upon to develop digital teaching and learning formats at short notice. This article aims to identify specific tasks and responsibilities with the help of two literature analyses and to transfer the results into a holistic overview of agile change for Flipped Classroom courses. This overview is based on a Change Management (CM) process to which tasks of agile development and change are assigned. It thus combines both short-term development under time pressure from an agile perspective as well as long-term necessary steps of CM. The necessity and usefulness of such an overview was determined before its creation. For this purpose, a short quantitative survey was conducted with 65 people, who have already passed through the entire CMprocess of digital change in higher education teaching and are therefore regarded as experts. The usefulness and necessity of the overview were confirmed. The concluding recommendations for action address the possible use of the overview, the implementation of individual tasks and the joint action of the stakeholders during and also after the Corona Pandemic, which should support the change to digital higher education teaching.

Keywords: agile change, Corona pandemic, digital university teaching, literature research, stakeholders

Cite this article as: Voigt, C., Blömer, L., Kötter, J., \& Hoppe, U. (2021). Agile Change to Digital Teaching during and after Corona Pandemic for Flipped Classroom Courses: An Overview of Tasks and Responsibilities. Journal of e-learning Research, 1(1), 11-22. https://doi.org/10.33422/jelr.v1i1.50

\section{Introduction}

The emergence of the Corona Pandemic in 2020 has changed public life internationally. In Germany, museums, restaurants, public places and international commercial enterprises are among those affected by weeks of closure, as are various educational institutions. With these measures, the Federal Government wants to prevent a further spread of the virus. It is still unclear how long German educational institutions will remain closed and from when on students and teachers will again be allowed to face each other personally in lecture halls, seminar rooms and consulting rooms. External pressure on German higher education institutions (HEI) is high. Digital learning formats are in demand in order to provide students with the necessary learning content even without attendance time. German HEI, which have so far been involved in digital teaching, supported it of their own motivation and less because of external influences so far (Schünemann et al. 2018). But such external influence is currently given by the Corona Pandemic. Stakeholders (SH) like 
university management and (scientific) staff are confronted with new challenges that have to be overcome in a short time. For example, numerous teachers were asked to digitize complete courses in the summer semester 2020 - regardless of their previous experience with digital teaching. This Corona-related change also affects other $\mathrm{SH}$.

The aim of this work is to support the affected SH during and after the Corona Pandemic in the successful transition to digital teaching formats. Thereby, the Flipped Classroom (FC) is chosen as a suitable course concept for the long-term use of digital contents and for improving digital teaching. In the past, findings on the effective design of Change Management (CM) processes (Herzfeldt et al. 2011), as well as on the use of agile methods (Gale et al. 2016; Vogel et al. 2015) have already proven their worth in the context of the emergence of digital teaching formats. Before such an overview can be established, the usefulness and usability of such an overview is first examined. Therefore, the first research question (RQ) of this paper is:

$R Q 1$ : Is an overview of tasks and responsibilities considered useful and relevant by the stakeholders, who are regarded as experts in digital change?

After $R Q 1$ had been confirmed by means of a written survey, FC related case studies were identified on the basis of two literature analyses in order to derive an overview of agile change from the tasks and responsible stakeholders mentioned there, which should serve as an orientation aid for those involved. The corresponding research questions are as follows:

$R Q 2 a$ : Which CM methods, tasks and responsible stakeholders can be identified by an initial literature analysis in case studies?

$R Q 2 b$ : Which agile methods, tasks and responsible stakeholders can be identified by a second literature analysis in case studies?

$R Q 3$ : What could a holistic overview look like in which the findings from $R Q 2 a$ and $R Q 2 b$ are transferred and what recommendations for action can be derived from this?

The research methods of this work are explained in Chapter 2. This involves a qualitative survey and two subsequent systematic literature analyses. The results of the analysis including quantitative and literature review are represented in Chapter 3. While the short quantitative survey addresses the first research question, $R Q 2 a$ and $R Q 2 b$ are answered by the presented $\mathrm{CM}$ methods, the agile methods and the tasks and responsible $\mathrm{SH}$ that could be identified in the case studies. Chapter 4 then presents an overview for agile change of FC courses, in which the relevant tasks are assigned to the responsible $\mathrm{SH}$ as well as to the $\mathrm{CM}$ process and the overview of an agile change in digital teaching. In addition, recommendations for action are derived for the $\mathrm{SH}(R Q 3)$. Chapter 5 summarises the results, discusses their limitations and shows possible future research paths that could follow this work.

\section{Research Methods}

In the context of this study, a short quantitative survey as well as two systematic literature analyses according to Webster and Watson were conducted (Webster and Watson 2002).

For the quantitative short survey, a total of 65 persons were interviewed, all of whom had already gained experience with digital teaching in various projects before the Corona Pandemic caused the closure of German HEI. This ensures that the participants do not make any assumptions, e.g. about the usefulness of a comprehensive overview of all tasks and responsibilities, but express their opinions as experts who have already carried out the entire 
CM process. In total, 41 students, 19 Teacher (+ Team), three IT and didactic (IT/D) Support staff and two persons from HEI Management took part at the survey. This was conducted anonymously and online using the university`s own software (Lime Survey).

The quantitative analysis is intended to examine the need for such an overview of existing tasks and responsibilities and is therefore prioritised. In general, we assume an overview as necessary when it is needed and helpful. In order to examine if it is needed, we asked in $Q 1$ whether the interviewees believe that further digital teaching concepts will emerge in the future. In order to verify, whether it is classified as helpful, $Q 2$ and $Q 3$ ask if it is useful both in general and in the context of the Corona Pandemic.

Q1: I believe that after the Corona Crisis more digital teaching formats will be offered than before.

Q2: I find an overview with all tasks and responsible groups of people generally useful in order to enable a structured transition to digital teaching.

Q3: In the context of the Corona Crisis, I would find an overview of all tasks/responsibilities useful.

The quantitative survey, should, therefore, answer the research question $R Q 1$.

In the second step, two systematic literature analyses are carried out, which form the basis for the answers to $R Q 2 a, R Q 2 b$ and $R Q 3$. Their aim is to combine the already proven processes of Change Management according to Kotter (Herzfeldt et al. 2011) with agile methods (Gale et al. 2016; Vogel et al. 2015). The literature analyses were carried out in four steps (1. identification of sources, 2. screening of sources, 3. testing of sources for their suitability and 4. inclusion of relevant sources) (Schryen 2015). As part of step 1, the databases AISnet, Google Scholar, Eric, Science Direct, Scopus and Web of Science, which are well established for information systems, were searched for (Schryen 2015). In order to be able to take into account findings from other relevant fields of education research, the database Eric (Education Resources Information Center) was also consulted (Webster and Watson 2002). The search and selection of suitable sources was carried out according to defined criteria, which led to the inclusion of relevant sources in the final step. Since the results of this work are intended to support affected SH both during and after the Corona Pandemic in successfully converting to digital teaching formats, it is important to consider how the digital teaching materials developed during the pandemic could be integrated into university teaching in the future. A suitable digital teaching concept that has already been successfully used in the past is the Flipped Classroom. In an FC, digital learning content is made available to students to prepare them for the attendance phase. Subsequently, the digitally acquired knowledge is reinforced by activating learning methods in the lecture hall (Bergmann and Sams 2012). FC courses have already demonstrated positive impacts for example on learning success and interaction between students so far (Voigt et al. 2020). During the Corona Pandemic, this face-to-face time must take place in the viral room or be cancelled. However, once HEI are reopened, the face-to-face time can take place in the lecture hall as usual. By introducing the Flipped Classroom, the newly created digital media may be used further on. In order to incorporate previous experience with this digital teaching concept, search terms of the FC were considered. Besides FC, the search term "Change Management" was used in the first literature analysis. In addition, publications from 2015 onwards were also considered to ensure that the contributions were up-to-date. In the six databases mentioned, 294 sources were identified. During the subsequent screening of the sources, 12 duplicates were removed. Subsequently, the suitability of the remaining 282 sources was checked 
with the help of defined exclusion criteria on the basis of the respective title, abstract and keywords. Exclusion criteria are a lack of CM focus, the lack of an FC or at least Blended Learning (BL) concept, no journal or conference contribution and no English or German text. This procedure reduced the number of sources to a total of 44 . The next step was to check the suitability of the sources by reading all 44 full texts and examining them again using fixed exclusion criteria. Sources, which were not case studies in the context of higher education teaching, and which dealt only rudimentarily with $\mathrm{CM}, \mathrm{FC}$ or BL, were considered unsuitable. In the end, this resulted in 7 relevant sources, the contents of which are explained in more detail in chapter 3.1. Besides FC, the search terms "Agile Process Model" and "Agile Development" were used in the second literature analysis. By searching the above-mentioned databases, 122 sources were identified. Six of them were duplicates which were not considered in the further selection process. In analogy to the first literature analysis, the suitability of the remaining 116 sources was then checked using defined exclusion criteria based on the respective heading, abstract and keywords. In this case, the exclusion criteria included a lack of reference to agile process models or agile development in connection with FC, a BL or at least an e-learning concept, and no English or German text. The remaining 13 sources were then read in order to subject them to the aptitude test. Apart from the consideration of the exclusion criterion of missing reference already mentioned, only contributions containing a case study were considered relevant. At the end of the second literature analysis, 3 sources could be designated as relevant.

The sources identified and the methods, tasks and responsible $\mathrm{SH}$ mentioned therein are presented in chapter 3 below. In each sub-chapter, an overview of the sources is provided first, showing the topicality and origin of the case studies. In order to then be able to answer $R Q 2 a$ in chapter 3.1 and $R Q 2 b$ in chapter 3.2, all sources were subjected to a structured search: While the methods used in the sources could mostly be clearly identified, the authors often had to derive the responsible $\mathrm{SH}$ and their tasks from the case studies and conclusions of the sources. In the course of both searches, several SH were identified, which were grouped into three groups as follows: One of these is the Teacher (+ Team), which, depending on the university and the size of the chair, is made up of academic staff, project staff, tutors and support staff. A further group is the IT/D Support, which, depending on the university, may act jointly or separately. Finally, there is the HEI Management, which includes both the university management and the faculty management. Occasionally, tasks were found which were not clearly assigned to clearly responsible SH. In these cases, the authors of this paper made an allocation by examining the task in the context of the source and then deriving responsible $\mathrm{SH}$. Furthermore, all tasks were assigned by the authors to a CM step according to (Kotter 1996).

\section{Results}

In the course of the quantitative evaluation, the identified $\mathrm{SH}$ groups were asked the three questions $Q 1-Q 3$. The first question of the survey $Q 1$ also refers to the long-term effects of the Corona Pandemic asking if the overview is needed: "I think that after the Corona Crisis more digital teaching formats will be offered than before". This question is affirmed by $80 \%$ of all respondents. With $83 \%$, the Teacher (+ Team) agreed the most with $Q 1$. The second and third questions Q2-Q3 address the helpfulness of such an overview. Q2 "I find an overview with all tasks and responsible groups of persons useful in order to drive the change to digital teaching" 
was answered with "Yes" by $90 \%$ of all respondents. Only $10 \%$ said that they did not consider an overview to be useful for driving the change. Of these, $100 \%$ agreed with the university management and the IT/D Support. Among the students surveyed, $89 \%$ of $Q 2$ and $88 \%$ of the Teacher (+ Team) agreed with $Q 2$. The last question $Q 3$ specifically addresses the coronarelated restrictions at the universities: "In the context of the Corona Crisis, I would find an overview of all tasks/responsibilities useful". Overall, the clear majority of all respondents also answered this question with "yes" by $89 \%$.

As there is clear agreement overall both on the relevance of a general overview of all tasks and responsibilities $(Q 1)$ and on relevance in the sense of expected long-term helpfulness $(Q 2-Q 3)$. In a nutshell, RQ1 can be confirmed and we therefore assume that an overview of all necessary tasks and affiliations is necessary and helpful.

\subsection{Methods, Stakeholder Und Tasks}

Of the seven sources identified as relevant, three were published in 2015 (Collyer and Campbell 2015; Hutchings and Quinney 2015; Liebscher et al. 2015), three in 2016 (Morisse 2016; Nordquist et al. 2016; Schoop et al. 2016) and one in 2018 (Van Twembeke and Goeman 2018). With regard to the places of implementation, three of the seven case studies are from Germany (Liebscher et al. 2015; Morisse 2016; Schoop et al. 2016), while one study was conducted in Sweden and the USA (Nordquist et al. 2016), one in Belgium (Van Twembeke and Goeman 2018), one in Australia (Collyer and Campbell 2015) and one in the United Kingdom (Hutchings and Quinney 2015). In four sources no CM method was used (Liebscher et al. 2015; Morisse 2016; Nordquist et al. 2016; Schoop et al. 2016). However, Van Twembeke and Goeman present a model in which CM and motivation are related. The model should help to ensure that learning with technology is increasingly accepted by teachers (Van Twembeke and Goeman 2018). Hutchings and Quinney, in turn, refer to the "Triple Helix Model" developed by them and another author, which looks at the three strands of research orientation, educational strategies and technology-enhanced learning that are designed to change learning experiences and university culture (Hutchings and Quinney 2015). Collyer and Campbell use Kotter`s CM Model to list successful practices that have been proven to support the learning process as new technologies are introduced (Collyer and Campbell 2015). This CM model by John P. Kotter contains eight steps to transform an organisation. It is based on Kotter`s observations of change processes in different organisations. Kotter noticed that these processes consist of a sequence of phases, none of which should be skipped (Kotter1996). Due to the step-by-step approach, Kotter's model is also used in this thesis for model development. The eight steps of Kotter's CM model are shown in chapter 4 in Figure 1.

As shown in Table 1, a total of 36 tasks could be identified, of which 16 tasks can be assigned to HEI Management and 12 to IT/D Support. Interestingly, the 12 tasks of IT/D Support are only found in steps 4-6 according to Kotters CM process, while the tasks of HEI Management are distributed between steps 2-5 and 7-8. For the Teacher (+ Team), eight tasks could be identified within the change process. With the exception of step 1, these are distributed throughout the entire CM process. As shown in Table 1, one third of the total of 36 tasks can be traced back to two, three or four sources. These include, for example, create framework conditions, which refers in particular to the provision of time, money and resources by HEI Management (Collyer and Campbell 2015; Hutchings and Quinney 2015; Liebscher et al. 2015; 
Van Twembeke and Goeman 2018). HEI Management should also promote exchange between teachers (Liebscher et al. 2015; Schoop et al. 2016) in order to reduce their prejudices and fears (Van Twembeke and Goeman 2018). IT/D Support, on the other hand, should create learning spaces/meeting points that enable interactive learning in large groups (Liebscher et al. 2015; Nordquist et al. 2016; Van Twembeke and Goeman 2018) or provide a common workspace for teachers to work on digital media (Van Twembeke and Goeman 2018). While the sources primarily refer to real spaces, during the Corona Pandemic these will be replaced by virtual spaces. Teacher (+ Team) should communicate their project to students by explaining their expectations and the event concept (Morisse 2016; Van Twembeke and Goeman 2018) as well as creating awareness of their workload (Morisse 2016; Van Twembeke and Goeman 2018). The task to communicate the advantages of e-learning is directed at all $\mathrm{SH}$, explaining to others the educational and financial benefits (Collyer and Campbell 2015).

\subsection{Agile Methods, Stakeholder and Tasks}

The studies identified in the second literature analysis were conducted between 2014 and 2016 in Europe and Africa and deal partly with identical and partly with different agile methods (Gale et al. 2016; Vogel et al. 2015). For example, two sources used Scrum (Gale et al. 2016; Vogel et al. 2015) and two sources used Just-in-Time-Teaching (JiTT) (Meissner and Stenger 2014) for the development of digital learning formats. Scrum is an agile process model that defines the sequence and the groups of people required to realise a project. Thus, the overall vision of the project is differentiated into several partial requirements that have to be realised per sprint in order to create a functional intermediate product of the overall vision. A sprint in turn consists of various individual phases that ensure a fast and agile procedure (Schwaber 1997; Sutherland and Schwaber 2013). JiTT, on the other hand, aims at the short-term adaptation of the presence phase, which is based on the previous preparation phase. In this method, teachers use the results of previously provided exercise materials to develop individualised teaching tailored to the student group (Novak 2011).

During the Ebola epidemic in Africa, Gale et al. adapted the Scrum processes to achieve even faster development of digital learning content. For the simulation of medical treatments, the authors used virtual reality in the form of gamification in order to be able to provide local health personnel with cost-effective continuing education that is as independent of time and place as possible. Skype was used for location-independent communication. This enabled the authors to develop an online simulation within three months (Gale et al. 2016). Vogel et al. also addressed Scrum during the development of an FC. In addition, a course was held taking JiTT into account. Learning materials and quizz questions were provided online for the students to prepare for the attendance time and were included in the attendance design. During the development, Skype was also used as a communication tool (Vogel et al. 2015). Meissner and Stenger also report on the use of JITT (Meissner and Stenger 2014). In the context of the subject "Electrical Engineering" at the TH Nürnberg, they designed a learning process with the help of JiTT that focused on the individual needs of the participants, among them both beginners and experts (Meissner and Stenger 2014). 
Table 1.

Responsible stakeholders ( $\mathrm{SH}$ ) and their tasks during the change.

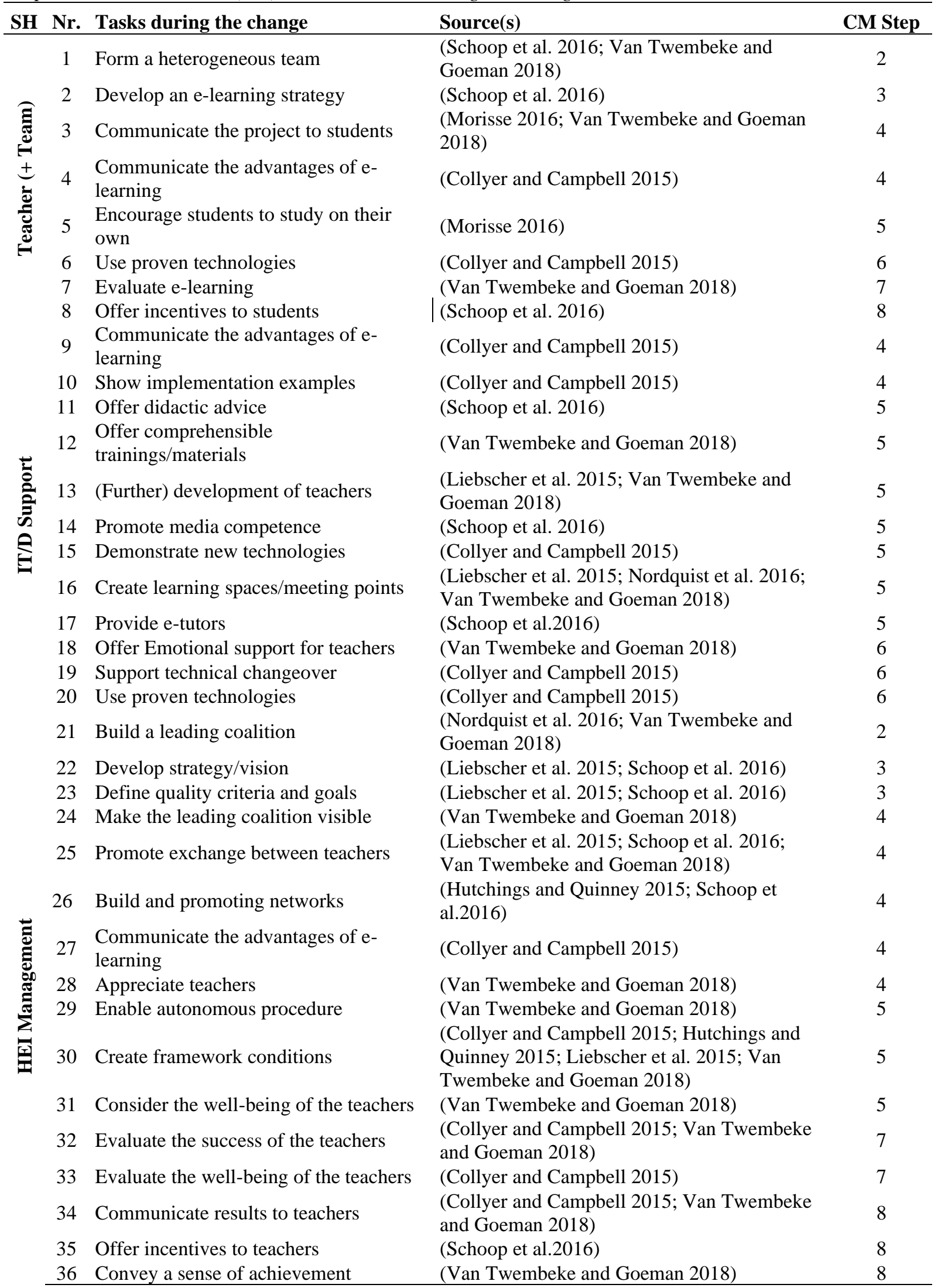


In Table 2 the tasks during agile development according to JiTT and Scrum are assigned to the eight CM steps according to Kotter (Kotter 1996). Overall it becomes clear that most tasks are the responsibility of Teacher (+ Team). Many of the tasks result from the Scrum process. In the task ensure efficient work, for example, the teacher, as Scrum Master, should coordinate his team and provide support if necessary. In the Sprint Planning Meeting it is important to define (sub)tasks and clarify responsibilities. The intermediate product of the task produce intermediate product, or the product increment can, for example, be the materials for a teaching unit, which are produced by the development team. In (Gale et al. 2016), the teachers and their team form a development team with IT/D Support. In the Retroperspective Meeting the task to learn from mistakes is mastered by analysing the previous sprint and identifying potential for improvement. As part of the task selecting software, (Vogel et al. 2015) selected software for development, whereas (Gale et al. 2016) and (Meissner and Stenger 2014) were looking for a finished learning tool. The authors Vogel et al. and Gale et al. also consulted external experts. In (Vogel et al. 2015), experts from the business world were recruited to establish a stronger link between science and practice. These experts came from different countries. In contrast, Gale et al. involved experts as infection control staff in order to be able to better meet the challenges of the epidemic (Gale et al. 2016).

Table 2.

Responsible stakeholders $(\mathrm{SH})$ and their tasks during the agile development.

\begin{tabular}{|c|c|c|c|c|}
\hline SH & Nr. & Tasks during the agile development & Source(s) & CM Step \\
\hline \multirow{20}{*}{ 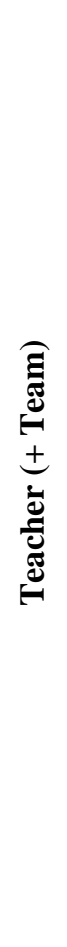 } & A & Acquire experts & (Gale et al. 2016; Vogel et al. 2015), & 2 \\
\hline & B & Define learning goals & (Meissner and Stenger 2014) & 3 \\
\hline & $\mathrm{C}$ & Identify needs and requirements & (Gale et al. 2016; Vogel et al. 2015) & 3 \\
\hline & $\mathrm{D}$ & Define (sub-) tasks & (Gale et al. 2016; Vogel et al. 2015) & 3 \\
\hline & $\mathrm{E}$ & Clarify responsibilities & (Vogel et al. 2015) & 3 \\
\hline & $\mathrm{F}$ & Select software & $\begin{array}{l}\text { (Gale et al. 2016; Meissner and Stenger 2014; } \\
\text { Vogel et al. 2015) }\end{array}$ & 3 \\
\hline & G & $\begin{array}{l}\text { Consider spatial, time and financial } \\
\text { restrictions }\end{array}$ & (Gale et al. 2016) & 3 \\
\hline & $\mathrm{H}$ & Select agile process model & (Gale et al. 2016) & 3 \\
\hline & I & Weigh up didactic methods & (Meissner and Stenger 2014) & 3 \\
\hline & $\mathrm{J}$ & Bring participants together & (Gale et al. 2016; Vogel et al. 2015) & 4 \\
\hline & $\mathrm{K}$ & $\begin{array}{l}\text { Select communication tool for } \\
\text { participants }\end{array}$ & (Gale et al. 2016; Vogel et al. 2015) & 4 \\
\hline & $\mathrm{L}$ & Communicate core elements & (Gale et al. 2016) & 4 \\
\hline & $\mathrm{M}$ & Ensure efficient work & (Gale et al. 2016; Vogel et al. 2015) & 5 \\
\hline & $\mathrm{N}$ & Produce intermediate product & (Vogel et al. 2015) & 6 \\
\hline & $\mathrm{O}$ & Software development & (Gale et al. 2016) & 6 \\
\hline & $\mathrm{P}$ & Build a learning platform & (Gale et al. 2016) & 6 \\
\hline & $\mathrm{Q}$ & Test the learning platform & (Gale et al. 2016) & 6 \\
\hline & $\mathrm{R}$ & Work out exercises & (Meissner and Stenger 2014) & 6 \\
\hline & $\mathrm{S}$ & Design presence phase & (Meissner and Stenger 2014) & 6 \\
\hline & $\mathrm{T}$ & Learn from mistakes & (Vogel et al. 2015) & 7 \\
\hline \multirow{3}{*}{ 圔 } & $\mathrm{U}$ & Weigh up didactic methods & (Gale et al. 2016) & 3 \\
\hline & $\mathrm{V}$ & Build a learning platform & (Gale et al. 2016) & 6 \\
\hline & W & Test the learning platform & (Gale et al. 2016) & 6 \\
\hline
\end{tabular}




\section{Agile Change to Digital Teaching at Higher Education Institutions}

In order to be able to derive recommendations for action for an agile change in times of the Corona Pandemic, an overview of agile change is presented in this chapter. Figure 1 visualises the overview, in which both CM tasks (numerical labelling) and tasks in the context of agile development (alphabetical labelling) were assigned to the eight steps according to Kotter and to the responsible stakeholders. Description and sources of the tasks can be found in Tables 1 and 2. Accordingly, Figure 1 illustrates when which stakeholders should take on which tasks according to previous research. It also becomes clear that most tasks of agile development are taken over by Teacher (+ Team), while most CM tasks concern HEI Management. However, the students were only indirectly involved in two tasks. As they are more likely to be the users of digital media and if at all involved in only a small part of the actual development, they are not included in the overview. The first step was to create a sense of urgency for the digital change caused by the closure of universities due to the pandemic. In the second step, the focus should be on the formation of teams, in which the Teacher (+ Team) and the HEI Management are involved. All internal and external participants and their roles are selected and acquired (1, 21, A). All SH are involved in step 3. Teacher (+ Team) work here primarily on the development of the e-learning strategy (2). This includes defining the learning objectives (B) and identifying the student's needs, from which the requirements for the e-learning strategy can be derived (C). These requirements are broken down into small subtasks in agile change and implemented piece by piece (D).

\begin{tabular}{|c|c|c|c|c|c|c|c|c|}
\hline & \multicolumn{7}{|c|}{ Agile Development with Scrum and JiTT } & \multirow[b]{2}{*}{8} \\
\hline Teacher (+ Team) & \multirow{3}{*}{$\begin{array}{l}\text { Urgency } \\
\text { arises from } \\
\text { pandemic- } \\
\text { related } \\
\text { university } \\
\text { closures }\end{array}$} & $1, \mathrm{~A}$ & $\begin{array}{l}\text { 2, B, C, D, } \\
\mathbf{E}, \mathbf{F}, \mathbf{G}, \mathbf{H}, \mathbf{I}\end{array}$ & $\begin{array}{c}3, \mathbf{4}, \mathrm{J} \\
\mathrm{K}, \mathrm{L}\end{array}$ & $5, M$ & $\begin{array}{c}6, \mathrm{~N}, \mathrm{O}, \mathrm{P} \\
\mathrm{Q}, \mathrm{R}, \mathrm{S}\end{array}$ & $7, \mathrm{~T}$ & \\
\hline IT/D Support & & & $\mathbf{U}$ & 9,10 & $\begin{array}{c}11,12,13, \\
14,15,16, \\
17\end{array}$ & $\begin{array}{c}18,19 \\
20, v, w\end{array}$ & & \\
\hline \multirow[t]{3}{*}{ HEI Management } & & 21 & 22,23 & $\begin{array}{c}24,25,26 \\
27,28\end{array}$ & $29,30,31$ & & 32,33 & $\begin{array}{l}34,35, \\
36\end{array}$ \\
\hline & $\begin{array}{l}\text { Step 1 } \\
\text { Establishing a } \\
\text { Sense of Urgency }\end{array}$ & $\begin{array}{l}\text { Step 2 } \\
\text { Forming a Powerful } \\
\text { Guiding Coaltion }\end{array}$ & \begin{tabular}{|l|} 
Step 3 \\
Creating a Vision
\end{tabular} & $\begin{array}{l}\text { Step } 4 \\
\text { Communicating } \\
\text { the Vision }\end{array}$ & $\begin{array}{l}\text { Step } 5 \\
\text { Empowering } \\
\text { Other to Act on } \\
\text { the Vison }\end{array}$ & $\begin{array}{l}\text { Step 6 } \\
\text { Planning for and } \\
\text { Creating Short- } \\
\text { Term Wins } \\
\end{array}$ & \begin{tabular}{|l|} 
Step 7 \\
Consolidating Improv- \\
ments and Producting \\
Still More Change \\
\end{tabular} & $\begin{array}{l}\text { Step 8 } \\
\text { Institutional- } \\
\text { izing New } \\
\text { Approaches }\end{array}$ \\
\hline & \multicolumn{8}{|c|}{ Managing the Change with the $\mathrm{CM}$ model according to Kotter } \\
\hline
\end{tabular}

Figure 1. Overview of agile change

Together with the IT/D Support, the ways and means of implementing the e-learning strategy are first defined (F, H, I, U, F). In times of a pandemic, the spatial and temporal limitations (G) must be considered in particular. While the tasks of the Teacher (+ Team) and the IT/D Support in Step 3 mainly stem from agile development, the CM tasks in this step are the main focus of HEI Management $(22,23)$. All three SH are also involved in Step 4. These include increasing visibility $(3,4,9,24,27)$ and promoting exchange among the $\mathrm{SH}(24,26, \mathrm{~J}, \mathrm{~K}, \mathrm{~L})$, as well as the appreciation of teachers by HEI Management (28). It must also be determined which tool is used for communication $(\mathrm{K})$, which is particularly important at times of spatial limitation due to the pandemic. Also in step 5 all SH take over tasks. The tasks are mainly in the area of $\mathrm{CM}$ and include didactic $(12)$ and technical $(14,15)$ training measures $(12,13)$ and the provision of e-tutors (17). This should create the conditions for independent $(5,29)$ and 
efficient work $(16,30, M)$. In step 6, on the other hand, the HEI Management has no tasks. Here, Teachers (+ Team) should use well-known and established technologies $(6,20)$ with the support of IT/D $(18,19)$, drive forward the development of the learning platform $(\mathrm{P}, \mathrm{Q}, \mathrm{V}, \mathrm{W})$ including the exercises (R, S, O). According to Scrum, success is achieved in small steps $(\mathrm{N})$. This development is exclusively anchored in the agile methods. Steps 7 and 8 are carried out by Teacher $(+$ Team) and the HEI Management. The seventh step involves the evaluation of the process $(7,32,33, \mathrm{~T})$, while the eighth step aims to anchor the approach by creating incentives $(8,35,36)$. Step 8 also includes only CM tasks.

After the tasks for each CM step and SH have been discussed in detail, the overview must be viewed from a top view in order to derive recommendations for joint action. It becomes clear that the shaping of change should primarily be guided by the HEI Management and initiated together with Teacher (+ Team). In order to build a strong leadership coalition in step 2, each teacher should be assigned at least one permanent contact person from IT/D Support. This is particularly important for Step 6, in which rapid success is to be achieved. In this phase, teachers are particularly dependent on the support of IT/D Support. An agile development with Scrum, however, which includes short, iterative phases, can only be successfully implemented if the responsible SH are clearly defined in advance. Step 2 should start with a joint meeting (virtual during the pandemic) to discuss the common approach and expectations. The procedural model, and the tasks it contains, can be used as a first, common orientation aid. SH with and without experience in digital teaching will benefit from the transparent presentation of the tasks, as this can lead to a better addressing of the participants and thus to a more efficient development of digital teaching formats. Although Kotter is of the opinion that CM steps should be addressed extensively and in a predetermined way in order not to cause lasting damage, external circumstances such as time pressure can lead SH having to skip individual steps or change the sequence of steps (Kotter 1996). Accordingly, it might be advisable for the HEI Management and the Teacher (+ Team) in step 2, in addition to the tasks listed in the procedure model, to devote themselves simultaneously to those tasks that can be traced back to more than two sources in Tables 1 and 2. These tasks include, for example, create learning spaces/meeting points and promote exchange between teachers. If the steps according to Kotter were strictly followed, these tasks would only arise in step 4 or 5. Under the assumption that tasks that can be traced back to several sources should be considered as particularly relevant, a preference for corresponding tasks could be purposeful. The procedural model for an agile transformation to digital teaching in HEI thus provides a signpost that should enable a successful transformation in the sense of Change Management and an agile approach. Particularly in times of the Corona Crisis and the external pressure to create digital media under time pressure, however, some of the tasks of Change Management, such as offer training (step 5) or communicate the results to teachers (step 8), may have been lost. These tasks, which could not be carried out during the change, need to be evaluated retrospectively and, if necessary, made up for. After all, agile change does not end with the creation of the online materials. A continuous evaluation is necessary to identify the weaknesses that have arisen due to the urgency of acting quickly. Thus, the current challenges caused by the Corona Pandemic could also represent an opportunity for digital change in university teaching. In this way, the knowledge and digital teaching formats gained during the pandemic could also be used and 
constantly improved in the future. For example, it would be conceivable for the period after the Corona Pandemic to integrate digital media into the online phase of a flipped classroom.

\section{Conclusion}

In this paper, tasks and responsibilities are presented and recommendations for action are derived for affected stakeholders in order to support an efficient transition to the digital teaching format, which could be adapted as a Flipped Classroom during or after the Corona Pandemic. To assess the significance of the topic, the first step was to conduct a survey on the relevance and usefulness of such an overview of tasks and responsible stakeholders $(R Q 1)$. The majority of the respondents were of the opinion that the Corona Pandemic favours the change to digital higher education teaching and that more digital teaching formats will be offered in the future than before. In addition, an overview of all tasks and responsible groups of persons was considered useful and sensible in order to be able to make a structured change to digital teaching during and also after the Corona Pandemic. In the next step, case studies were identified on the basis of two literature analyses in order to analyse already used models. A total of 59 tasks and 3 responsible stakeholders with regard to CM (RQ2a) and the agile development of digital learning formats could be found $(R Q 2 b)$. These tasks and responsibilities result in a general overview which can serve as a guide for agile change during the Corona Pandemic. Based on the general overview, recommendations for action are then formulated for the various stakeholders (RQ3). The added value of the overview lies particularly in the presentation of specific tasks and the clear allocation of responsibilities to the various stakeholders. By enabling the participants to see not only their own tasks but also those of the other stakeholders, the need for constructive cooperation between the stakeholders becomes clear. This transparency should create a common understanding and thus enable smooth and efficient action.

The limits of this work are on the one hand the limitations of the literature analysis, which is exclusively based on case studies. On the other hand, they are to be found in the number of participants for two of the stakeholder groups considered. Moreover, the overview cannot be universally transferred to other framework conditions, but must be adapted to the conditions of the respective HEIs. Future research could evaluate the overview with regard to relevance and the allocation of responsibilities from the perspectives of different stakeholders within different framework conditions. In addition, it is necessary to determine whether other tasks have arisen during the pandemic, which have not yet been considered in the overview presented. In the future, the effects of the pandemic on the various stakeholders, their cooperation and solutions as well as identified challenges, needs for action and potential for improvement for digital change should also be evaluated. The long-term consequences of the Corona Pandemic could also be researched in future studies. On the one hand, it must be investigated whether the pandemic actually leads to a long-term increase in digital teaching, as predicted by the stakeholders surveyed.

\section{References}

Bergmann, J., and Sams, A. 2012. Flip Your Classroom: Reach Every Student in Every Class Every Day, Alexandria: International Society for technology in Education. 
Collyer, S., and Campbell, C. 2015. "Enabling Pervasive Change: A Higher Education Case Study," in EdMedia+ Innovate Learning, Association for the Advancement of Computing in Education (AACE), pp. 249-255.

Gale, T. C., Chatterjee, A., Mellor, N. E., and Allan, R. J. 2016. "Health Worker Focused Distributed Simulation for Improving Capability of Health Systems in Liberia," Simulation in Healthcare (11:2), pp. $75-81$.

Herzfeldt, A., Kristekova, Z., Schermann, M., and Krcmar, H. 2011. "A Conceptual Framework of Requirements For The Development of E-Learning Offerings From a Product Service System Perspective," in AMCIS, pp. 1-10.

Hutchings, M., and Quinney, A. 2015. The Flipped Classroom, Disruptive Pedagogies, Enabling Technologies and Wicked Problems: Responding to 'the Bomb in the Basement, `(13:2), pp. 106119.

Kotter, J. P. 1996. Leading Change: Why Transformation Efforts Fail, p. 12.

Liebscher, J., Petschenka, A., Gollan, H., Heinrich, S., Van Ackeren, I., and Schmid, S. 2015. "ELearning-Strategie an Der Universität Duisburg-Essen-Mehr Als Ein Artefakt," Zeitschrift Für Hochschulentwicklung (10:2), pp. 97-109.

Meissner, B., and Stenger, H.-J. 2014. “Agiles Lernen Mit JustTinTTimeTTeaching,” Teaching Trends 2014, p. 121.

Morisse, K. 2016. "Inverted Classroom in Der Hochschullehre-Chancen, Hemmnisse Und Erfolgsfaktoren," in Das Inverted Classroom Modell. Begleitband Zur 5. Konferenz Inverted Classroom and Beyond, pp. 1-11.

Nordquist, J., Sundberg, K., and Laing, A. 2016. "Aligning Physical Learning Spaces with the Curriculum: AMEE Guide No. 107,” Medical Teacher (38:8), pp. 755-768.

Novak, G. M. 2011. “Just-in-Time Teaching,” New Directions for Teaching and Learning (2011:128), pp. 63-73.

Schoop, E., Köhler, T., Börner, C., and Schulz, J. 2016. Consolidating ELearning in a Higher Education Institution: An Organisational Issue Integrating Didactics, Technology, and People by the Means of an ELearning Strategy, p. 12.

Schryen, G. 2015. "Writing Qualitative IS Literature Reviews--Guidelines for Synthesis, Interpretation, and Guidance of Research," Communications of the Association for Information Systems (37), pp. $286-325$.

Schünemann, I., Budde, J., and für Hochschulentwicklung, C. C. 2018. "Hochschulstrategien Für Die Lehre Im Digitalen Zeitalter," Keine Strategie Wie Jede Andere.

Schwaber, K. 1997. "Scrum Development Process," in Business Object Design and Implementation, Springer, pp. 117-134.

Sutherland, J., and Schwaber, K. 2013. "The Scrum Guide," The Definitive Guide to Scrum: The Rules of the Game. Scrum. Org (268).

Van Twembeke, E., and Goeman, K. 2018. "Motivation Gets You Going and Habit Gets You There," Educational Research (60:1), pp. 62-79.

Vogel, B., Kilamo, T., and Kurti, A. 2015. "Teaching Distributed Agile Development to Software Professionals: A Flexible Approach," in Proceedings of the 2015 European Conference on Software Architecture Workshops, ACM, p. 31.

Voigt, C., Blömer, L., and Hoppe, U. 2020. The Course Design Does Matter: Analyzing the Learning Success of Students.

Webster, J., and Watson, R. T. 2002. "Analyzing the Past to Prepare for the Future: Writing a Literature Review,” MIS Quarterly (26:2), pp. xiii-xxiii. 